\title{
A Classification of Supply Chain Problems
}

\author{
Beverly E. Osborn ${ }^{1} \&$ Barrie R. Nault ${ }^{1}$ \\ ${ }^{1}$ Haskayne School of Business, University of Calgary, Calgary, Canada \\ Correspondence: Barrie R. Nault, Haskayne School of Business, University of Calgary, 2500 University Drive \\ NW, Calgary, AB, T2N 1N4, Canada. Tel: 1-403-282-0095. E-mail: nault@ucalgary.ca
}

Received: May 1, 2012 Accepted: June 2, 2012 Online Published: July 11, 2012

doi:10.5539/emr.v1n2p1 URL: http://dx.doi.org/10.5539/emr.v1n2p1

\begin{abstract}
Supply chain problems referenced in peer-reviewed journals and selected management magazines were collected, with information about the journal, the resource affected, the cause of the problem, the solution(s) applied, and the firm(s) involved. Keywords were used to group these problems into naturally occurring categories. Nine types of supply chain problems were identified: conflict, delays, demand fluctuations, excess/unused resources, inaccuracy, insufficient resources, long tail, pricing, and security. These categories together present a comprehensive view of problems that typically affect different resources within the supply chain, and can be used to diagnose problems and to evaluate solutions.
\end{abstract}

Keywords: supply chain, problem, typology, classification, literature review

\section{$1 \square$ Introduction and Literature}

\subsection{Motivation}

Supply chain problems have a significant impact on profitability, not only at a single firm, but potentially at the many firms involved in almost any given supply chain. This research seeks to develop a comprehensive view of the types of supply chain problems that occur in modern industry through an analysis and classification of supply chain problems referenced in the academic literature.

A supply chain problem, for our purposes, is a specific and localized issue with negative effects on one or more firms involved in a supply chain. That is, we do not consider macroeconomic and broader issues. We do not consider the absence of a beneficial technology a supply chain problem, although the results of its absence may be. An example is the $8 \%$ error rate in orders placed by Geon at OxyVinyl (Hammer, 2001), which was eventually improved upon through technology enabled integration between the companies. Problems in supply chains at this level generally stem from deeper problems such as misaligned incentives (Narayanan \& Raman, 2004), lack of visibility either between or within firms (Barratt \& Barratt, 2011), and lack of agility in responding to changing market conditions (Lee, 2004).

Performance improvements in supply chains can be achieved through increased integration of material and information flows between firms (Rai et al., 2006). Investments in supply chain management technologies have improved financial performance metrics for incoming and outgoing processes on the firm level (Dehning et al., 2007). Yet it is well known that not all technology investments deliver equal returns; investments must be aligned with business processes and objectives in order to deliver projected benefits.

A classification scheme for supply chain problems, at a level easily observed by supply chain practitioners and based on criteria which can be easily recognized as signs of supply chain problems, allowing for the identification of connections between symptoms and solutions. It also provides a straightforward method for academics to assess the applicability of proposed improvements, technological and otherwise, to individual supply chain issues.

\subsection{Supply Chain Problems}

Broad solutions to supply chain problems are given in several articles. Lee (2004) recommends that a supply chain be agile, adaptable, and aligned, and Andriole (2006) suggests that information technology (IT) investments should be made to improve collaboration and integration in the supply chain. These suggestions are given to all supply chains, regardless of the type of problem. 
In contrast, the supply chain problems mentioned are typically quite specific. Fryer's (2001) interview with Stolle refers to a component shortage that interfered with Sony's launch of the Playstation2, while Shoenherr and Mabert (2008) cite an anonymous firm whose bundles sometimes did not receive any bids at online auction.

A midpoint in specificity does exist in Manuj and Sahin's (2011) discussion and classification of the antecedents of supply chain complexity. The article includes examples from practice, including rapidly changing technologies and manufacturing dispersion, which negatively impact performance outcomes and contribute to problems such as those analyzed in this work, but the focus is on causes of problems, rather than on the problems themselves.

This contrast between broad solutions and specific problems is appropriate when a given solution is applicable to a broad range of problems. However, this universal applicability has not been demonstrated, and in the absence of a comprehensive set of problem types it is difficult to assess the universality of a particular supply chain solution.

\subsection{Problem Classification}

The grouping or classification of objects under investigation is an important step in any discipline of scientific inquiry (Carper \& Snizek, 1980). Although no broad classification scheme for supply chain problems was found, such categorizations have been created for the analysis of problems in many other fields.

Bean and Kuh, who present a typology of planning problems in educational institutions, argue that their typology is useful for three reasons. It "helps to reduce many seemingly disparate issues and concerns into a relatively small number of categories, ... encourages richer descriptions and more exact distinctions between the different types of problems, ...(and reduces) the amount of time individual planners must devote to identifying issues" (p $36,1984)$.

In his taxonomy of decision problems, Scherpereel (2006) suggests that academics are sometimes so focused on finding solution methodologies for ideal problems that the differences between problems may be overlooked until these methodologies are applied to real world situations. This suggests that, as it has in other disciplines, a classification scheme for supply chain problems can provide a useful connection between research and industry.

Nickols (1996) classifies quality problems by appropriate problem-solving methodology, as prompted by an industry practice of using one structured approach for all quality problems; the classification scheme is expanded in Smith (2000) who uses the five problem categories of conformance, unstructured performance, efficiency, product design, and process design. This classification system can be applied to supply chain problems, however this does not yield the comprehensive and specific picture of supply chain problems which is sought by our work.

A more targeted approach is taken by MIT's Center for Transportation and Logistics, which identifies six ways that supply chains fail following disruptive events. Each involves the loss of capacity to perform one of the following: acquire materials, ship or transport, communicate, convert, use human resources, or tap financial flows (Rice, 2011). Although suited to its purpose, this typology does not create a truly comprehensive view of supply chain problems - the stated objective of our work - as it disregards problems (such as excess capacity) which occur in supply chains not suffering from disruptive events.

A supply chain specific classification of problems should be useful for many of the same reasons that problem classification has proven useful for other fields, i.e., for streamlining the problem-solving process (Bean and Kuh, 1984), and ensuring that the differences between problems are given suitable attention (Scherpereel, 2006).

\section{2匹 Methodology}

\subsection{Unit of Analysis}

Supply chain problems are a more appropriate unit of analysis for this research than supply chain solutions would be, as technologies are less static than the problems they resolve. In addition, problems are relatively objective. Cognitive factors such as hindsight bias (Fischhoff, 1975) may skew solutions in cases with known outcomes. Solutions may also be too multifaceted for this method of analysis, as initiatives often have multiple objectives (e.g., increasing product availability and reducing inventory costs (Slone, 2004).

\subsection{Problem Identification}

An initial search of the relevant literature was undertaken for selected top journals and management magazines using the ABI/Inform Global Database. Initial search terms included supply chain, supply chain management, information systems, B2B, value chain, and logistics. As the literature review continued potentially related 
references to research outside the selected set were followed in order to achieve a more comprehensive view of the academic literature.

At times the identification of the problem was complex, e.g., when an anonymous machine tool distributor encountered congestion related delays at the Port of Los Angeles Long Beach (Manuj \& Sahin, 2011). This might have been considered a problem of insufficient capacity for the port, but for the distributor it would be considered a problem of freight delays. In the interests of consistency, if only one party was named in the reference then the problem was approached from that party's perspective. If no party was named, or if more than one was, then the problem was approached from the viewpoint of the company more central to the issue.

Another issue to be resolved in the problem identification process involved multi-layered problems, e.g., when the shareholders of Bristol-Meyers sued the company after share price fell following distorted expectations caused by forward buying (Lee, Padmanabhan \& Whang, 1997). Although this article does not intend to burrow down to root causes when identifying problems, it is clear that only one of these four stages is actually a supply chain problem - namely forward buying - while the others are financial and legal issues resulting from it.

Where multiple references were found to the same supply chain problem (e.g., Cisco's surplus write-off of 2001; Lee, 2004; Narayanan \& Raman, 2004), only the more detailed mention was used to avoid skewing the data with redundant mentions of higher-profile events.

Table 1. Sources

\begin{tabular}{lc}
\hline Articles Contributing to Problem Set & 41 \\
\hline Mean Publication Year & 2002 \\
Range of Publication Year & $1992-2011$ \\
Max Problems per Article & 14 (Lee, 2004) \\
Mean Problems per Article & 2.68 \\
\hline
\end{tabular}

The articles that contributed to the problem set had a range of publication dates from 1992 to 2011, with a mean publication year of 2002. This sample is sufficiently recent that findings should be relevant to supply chain problems which arise in the present and near-future. Given that a date of occurrence was not given for the majority of the problems, it cannot be assumed that problems are similarly distributed or similarly timely. Approximately half (20/41) articles contributed more than one problem, with Lee's "The Triple-A Supply Chain" from 2004 contributing the greatest number (14/110). The mean number of problems contributed per article is 2.68 .

\subsection{Firms and Industries}

References were found to 110 supply chain problems. The majority of these are attributed to specific, identified, firms (74/110). Company names are subject to change; those given here are as per the reference cited. Sixteen problems were not company specific. These generic problems are included in order to ensure that a picture which is as comprehensive as possible is created. In some cases the reference was to a problem widespread in a particular industry (e.g., the bullwhip effect as experienced by the semiconductor industry, Lee (2004)). In others the industry is also unidentified. Some problems were attributed to specific firms, but the firm name was not given (e.g., Shoenherr \& Mabert, 2008). In these cases the firm is listed as Anonymous (20/110).

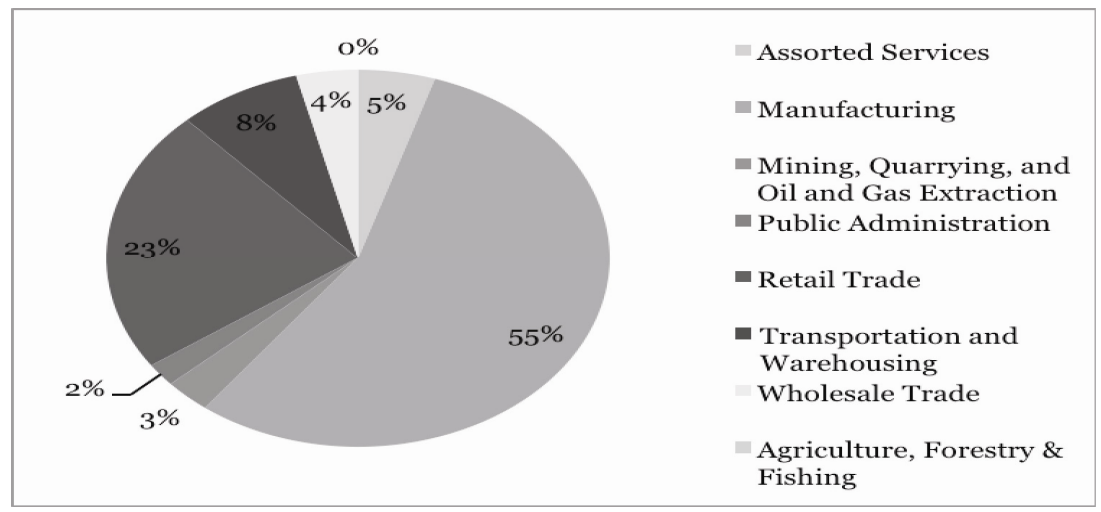

Figure 1. Industry sectors represented in data 
The firms which were identified belong to a variety of industries, and have a distribution which is reasonably similar to the distribution of industries referenced elsewhere in supply chain management literature. In the case of vertically integrated firms, the industry immediately involved in the problem was used (i.e., if a problem involved the manufacturing operations of a firm it was identified as a manufacturing firm, even if retail comprised a greater proportion of the firm's overall operations). Based on the North American Industry Classification System's two digit codes, Figure 1 shows the distribution of industry sectors represented in our dataset of supply chain problems.

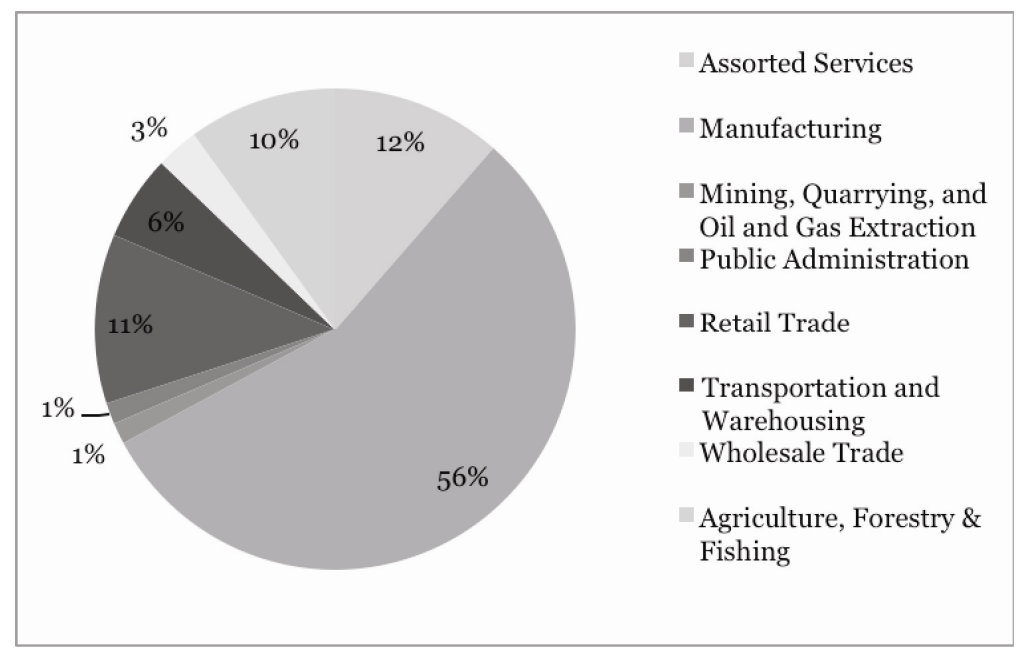

Figure 2. Industry sectors represented in burgess et al., 2006

For comparison, Figure 2 shows the distribution of industry sectors represented in Burgess et al's structured review of supply chain management literature (2006). Both sets are somewhat amalgamated. Specifically, the 5 assorted services in our dataset consist of 1 firm from a Finance and Insurance industry and 4 firms from Information and Cultural industries. The 8 assorted services from Burgess et al included 1 Construction industry, 5 Communication Services industries, 1 Education industry, and 1 Personal and Other Services industry.

The greatest differences between the sets are the absence of examples from agricultural, forestry and fishing in our dataset, and the greater representation of retail. The two sets of industry distributions are not directly comparable due to different units of analysis, but they do indicate that this problem set displays some patterns characteristic of supply chain management research, such as an emphasis on the manufacturing sector

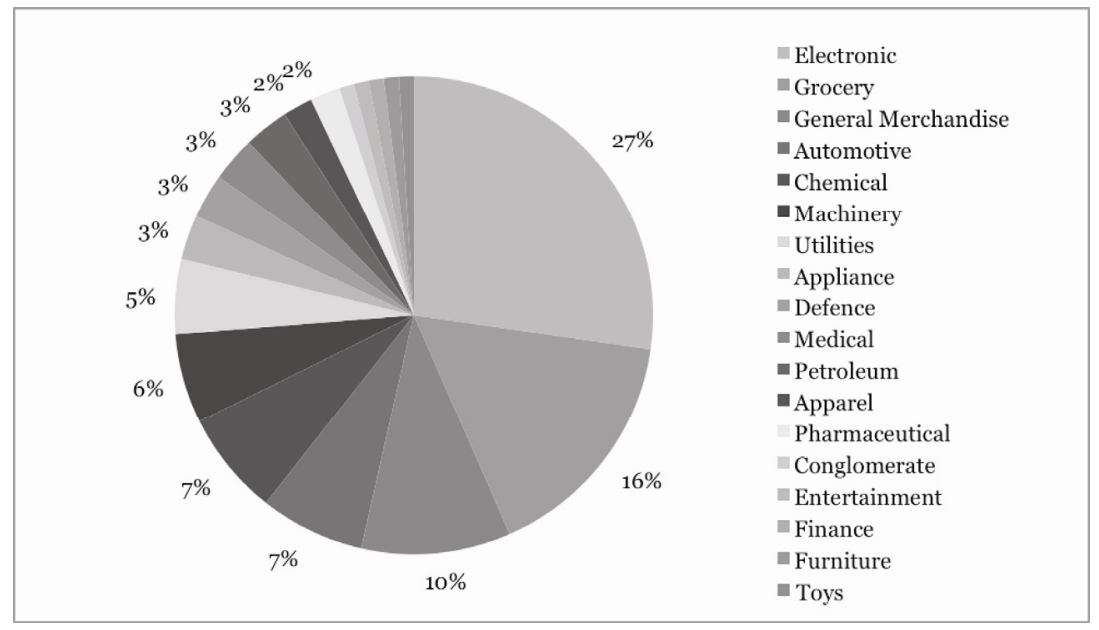

Figure 3. Product supply chains represented in the studies 
In Figure 3 we break down the industry data in another way, by product rather than industry sector. It is apparent that although many different supply chains are represented, there is more extensive coverage of some than of others. This also reflects patterns observed elsewhere in supply chain management research, which has previously been noted to have relatively extensive coverage of the electronics, machinery and automotive sectors (Liu \& Deitz, 2011), and of consumer goods retail (Burgess et al., 2006).

\section{Classification System}

\subsection{Overview and Resources}

One of the requirements of classification schemes is to establish mutually exclusive and exhaustive groups (Doty \& Glick, 1994). Each of the problems examined here can be attributed to one of three different resources: material (which includes freight, inventory and product), information, and relationship. The literature review identified no instances of problems with the flow of finances between companies, which is in keeping with previous analysis: Rai et al. (2006) examined the flows of information, material and finances between firms and found that financial integration was high and insignificant. Therefore financial flows are not discussed further. Relationships are, in contrast, a significant source of problems in supply chains. Relationships are important as they may provide a more sustainable advantage than other assets, being less imitable and mobile (Barratt \& Oke, 2007). Relationship based problems, e.g., high switching costs, would be difficult to attribute directly to the flow of either material or information, but nonetheless play a significant role in some supply chains.

Aside from characterizing problems by resource, keywords are also assigned. These keywords more specifically describe each problem; each keyword is a typical problem affecting one or more specific resources. After a short discussion of each resource, we examine individual keywords as they apply to each resource and present characteristic examples, as well as the solutions which were either applied to or recommended for these problems in the literature. The solutions mentioned are not intended to be comprehensive, as that would be beyond the scope of this research.

\subsubsection{Material}

The category of material is amalgamated from those of freight, inventory and product. These are all areas involving the tangible good (or service), with freight referring to the transportation of the material, inventory being the quantity and storage of the material, and product involving attributes of the material itself. Keeping these three aspects of the flow of material separate was done with the goal of presenting a comprehensive picture of supply chain problems in mind; freight capacity and inventory quantity are different problems with different solutions, and these differences should not be disregarded unnecessarily.

Problems of inventory could feasibly be simplified to the level of too much or too little, but such a degree of amalgamation would erase the real differences between types of problems, and a more specific approach has been taken. Inventory problems discussed here include unexpected demand fluctuations and long tail distributions as well as the expected overstocks and shortages.

Typical freight problems involve delays and distance, although quantity problems do occur here as well. Long distances in the supply chain can reduce responsiveness, particularly in industries involving some degree of customization (Cattani et al., 2005). Delays are major contributors to long or variable lead times, which reduce inventory turnover (Rabinovich et al., 2003).

The final category of material problems, that of product, is perhaps the least expected in a supply chain context. It is dominated by pricing problems, including process inefficiencies (e.g., excessive manual intervention) that drive up expenses and result in higher, even non-competitive, end-product prices.

\subsubsection{Information}

Information flows are often mediated by information technologies such as e-commerce and EDI, although they do also include direct person-to-person communication. Information flows have been shown to affect material flows, allowing for improved coordination and performance metrics (Barratt \& Barratt, 2011; Klein \& Rai, 2009; Sanders, 2007). Despite this interaction, many problems are discussed squarely in the context of information. For example, IBM customers incorrectly entering their orders (Hammer, 2001) is clearly a problem of inaccurate information and not a problem of product delivery - although it may interfere with product delivery effectiveness. As well as inaccuracy, information channels experience problems with security, quantity (i.e., excess/unused resources and insufficient resources) and delays. The security problems identified involve mistrust interfering with the flow of information between members of a supply chain; information flows are positively affected by trust (Klein \& Rai, 2009). The increasing impact of return flows, particularly on e-commerce supply 
chains, also involves information flows as the dissemination of product information in suitable quantities may be more difficult on the internet (van Hillegersberg, 2001).

\subsubsection{Relationship}

Relationship is a more abstract concept than either material or information. It refers to the nature of the parties involved and the connection between them. Problems particular to relationships include ambiguity and conflict over issues such as contract terms, expectations, roles, or objectives. Problems with insufficient and unused resources also impact this category; several references were made to firms which were unable to implement technological solutions because of the lack of necessary skills in their supply chain partners (e.g., Rosenzweig \& Roth, 2007). Excess/unused resources in this category include dissipated buying power, and redundant relationships. Finally, pricing issues also impact relationships, as when revenue models misalign incentives and result in losses, write-offs, and other negative outcomes (Narayanan \& Raman, 2004). The often-high costs of exiting an ineffective relationship are another variety of relationship pricing problem.

\subsection{Types of Problems}

\subsubsection{Conflict}

Table 2. Conflict

\begin{tabular}{lcccc}
\hline Keyword & $\begin{array}{c}\text { Frequency } \\
(\mathrm{n}=110)\end{array}$ & Resource & Example Problems & Example Solutions \\
\hline Conflict & 9 & Relationship & $\begin{array}{c}\text { Power imbalance (e.g., forced joint } \\
\text { venture), role conflict (e.g., } \\
\text { cooperating with competitors), } \\
\text { differing objectives }\end{array}$ & $\begin{array}{c}\text { Incentive alignment, } \\
\text { enhanced trusting beliefs } \\
\text { (e.g., through contingency } \\
\text { based hostages) }\end{array}$ \\
\hline
\end{tabular}

Conflict problems affect relationships, and occur when the goals of the parties involved are opposed, misaligned, or unclear. There is an inherent conflict of interest in supply chains, as the optimal course of action for any individual firm in the supply chain may differ from the optimal course of action for the whole supply chain, as demonstrated in the behavior of U.S. automotive dealerships in Leeuw et al. (2011). Although these dealerships were found to vary in their individual inventory management strategies, in general customers frequently had to compromise on desired specifications, as dealers preferred to sell from their own stock (as opposed to having a vehicle made-to-order). It was concluded that dealerships act in their own best interests, as opposed to the best interests of the whole supply chain. This self-interest may also prevent competitors from forming cooperative relationships with one another (e.g., Baxter's competitors preferred not to have their products carried on a distribution channel controlled by Baxter (Short \& Venkatraman, 1992)). Conflict also arises from competition over the margin pie (Myers \& Cheung, 2008), and even internal, interpersonal conflicts between departments or individuals may interfere with productivity (e.g., departments concealing inventory from one another in Sawy et al, 1999). Parties may also be unsure of their role in a situation, as occurs in role conflict, which arises from disagreement about objectives, methods, or identity (Koch \& Schultze, 2011). Alternatively it may arise in the interpretation of agreements which are not made explicit, as when Cisco suppliers "believed that Cisco had implicitly assured them it would buy everything they could produce" (p 96, Narayanan \& Raman, 2004).

\subsubsection{Delays/Distance}

Table 3. Delays

\begin{tabular}{lllll}
\hline Keyword & $\begin{array}{l}\text { Frequency } \\
(\mathrm{n}=110)\end{array}$ & Resource & Example Problems & Example Solutions \\
\hline Delays & 10 & Freight & $\begin{array}{l}\text { Shipping delays (e.g., post ERP } \\
\text { installation), port congestion, failure to } \\
\text { deliver as promised, material not } \\
\text { always moving, long lead times, } \\
\text { inefficient or unsuitable transportation } \\
\text { routes }\end{array}$ & $\begin{array}{l}\text { Automation, real-time } \\
\text { information sharing, } \\
\text { increased safety stock, } \\
\text { postponement, relocation, } \\
\text { incentive alignment }\end{array}$ \\
& & & $\begin{array}{l}\text { Translation step between IT systems, } \\
\text { indirect flows, information arrives after } \\
\text { required response }\end{array}$ & $\begin{array}{l}\text { Automation, integration of } \\
\text { IT, postponement of } \\
\text { production until information } \\
\text { is available }\end{array}$ \\
\hline
\end{tabular}


Freight delays are fairly self-explanatory problems. Late deliveries can have severe consequences, even halting production in supply chains where JIT processes are used, as happened at Toyota plants following the Sendai earthquake (Rice, 2011). They also severely impact customer satisfaction: a survey funded by Whirlpool and Sears indicated that the most important factor for customer satisfaction with appliance delivery was fulfillment of date commitments (Slone, 2004). Delays can also result from a supply chain crossing unnecessarily long distances. Long distances in the interests of cost savings are not a problem, but distances travelled due to a lack of responsiveness to change are. An example is Lucent, which sourced raw materials from Asia but manufactured products in the United States, despite its customer base having shifted to Asia, which resulted in higher prices and inferior customer responsiveness when compared to competitors (Lee, 2004).

Information delays affect the usability of the information involved. If relevant information arrives after a given decision has been made, the information cannot be acted upon (e.g., ordering decisions are frequently made before market testing data arrives (Fisher et al., 2000)) and is therefore useless. Less severely, delays can affect efficiency, as when indirect information flows create extra steps in a process (e.g., Barratt \& Barratt, 2011).

\subsubsection{Demand Fluctuations}

Table 4. Demand fluctuations

\begin{tabular}{|c|c|c|c|c|}
\hline Keyword & $\begin{array}{l}\text { Frequency } \\
(n=110)\end{array}$ & Resource & Example Problems & Example Solutions \\
\hline $\begin{array}{l}\text { Demand } \\
\text { Fluctuations }\end{array}$ & 13 & Inventory & $\begin{array}{l}\text { Demand changes faster than } \\
\text { production cycles, bullwhip } \\
\text { effect, high inventory costs, } \\
\text { stockouts, ramping up and } \\
\text { down production may cause } \\
\text { defects }\end{array}$ & $\begin{array}{l}\text { Incentive alignment, standardization } \\
\text { and integration of IT, shared } \\
\text { resources (e.g., consortia), reduce } \\
\text { promotions, use POS for } \\
\text { forecasting, CPFR, flexible } \\
\text { manufacturing }\end{array}$ \\
\hline
\end{tabular}

Demand fluctuations, for our purposes, refers only to unexpected demand variability. Unexpected demand fluctuations make it hard for a company to stock the appropriate amount of inventory, resulting in too much at some times and too little at others. These problems (the most frequently cited in this data set) may be caused by the bullwhip effect, which is associated with practices such as promotions and forward buying (Lee et al, 1997). The bullwhip effect is a phenomenon in which order variability increases as it moves upstream in the supply chain. Cachon et al (2007), demonstrate that in industries with high seasonality production smoothing is a stronger force than the bullwhip effect (i.e., order variability decreases as it moves upstream); seasonal demand fluctuations are unlikely to cause problems due to their relative predictability. On an operational level, problems occur when demand varies too quickly and unpredictably for a company to respond (e.g., machine tool distributors had difficulties handling large turnkey contracts (Narus \& Anderson, 1996)). Even when production is responsive enough to accommodate unexpected demand fluctuations, it may lead to side-effects such as increased product defects (Lee, 2004). Demand fluctuations can be reduced with information sharing in the supply chain, which has the benefit of reducing inventory holding costs (Dehning et al., 2007).

3.2.4 Excess/unused resources

Table 5. Excess/Unused Resources

\begin{tabular}{lcccc}
\hline Keyword & $\begin{array}{c}\text { Frequency } \\
(\mathrm{n}=110)\end{array}$ & Resource & Example Problems & Example Solutions \\
\hline $\begin{array}{l}\text { Excess/unused } \\
\text { resources }\end{array}$ & 10 & Inventory & $\begin{array}{c}\text { Low inventory turnover, } \\
\text { markdowns and scrap, } \\
\text { decreased liquidity }\end{array}$ & $\begin{array}{c}\text { ECR, CPFR, incentive } \\
\text { alignment, integration, } \\
\text { continuous replenishment, } \\
\text { reduced lead times and lead time } \\
\text { variability (e.g., JIT) }\end{array}$ \\
$\begin{array}{l}\text { Excess/unused } \\
\text { resources }\end{array}$ & 5 & Freight & $\begin{array}{c}\text { Duplication of assets, less } \\
\text { than full truckloads (other } \\
\text { modes as well) }\end{array}$ & $\begin{array}{c}\text { Emarketplace use, cosupplier } \\
\text { relationships, load assortment or } \\
\text { consolidation, outsourcing, } \\
\text { incentivize full loads }\end{array}$ \\
Excess/unused & 2 & Information & Unfavourable test results & Automation, integration of IT, \\
\hline
\end{tabular}




\begin{tabular}{|c|c|c|c|c|}
\hline resources & & & $\begin{array}{l}\text { ignored, duplication of } \\
\text { efforts due to information } \\
\text { not being shared } \\
\text { appropriately }\end{array}$ & track information accuracy \\
\hline $\begin{array}{l}\text { Excess/unused } \\
\text { resources }\end{array}$ & 3 & Relationship & $\begin{array}{l}\text { Dissipated buying power, } \\
\text { relationship redundancy }\end{array}$ & $\begin{array}{l}\text { Centralized procurement, assess } \\
\text { uses for preexisting relationships }\end{array}$ \\
\hline
\end{tabular}

High levels of inventory are associated with long lead times, high uncertainty, large batch sizes, demand variability, seasonality, high target service levels, and speculation (Leeuw et al., 2011). In the face of uncertainty inventory provides a useful buffer, but it also involves holding costs, reduces liquidity, and introduces risks of damage and obsolescence. Some uncertainty can be avoided with integration between firms in a supply chain: when Geon divested its non-core raw materials production operations into a separate company working capital rose $12 \%$, inventory $15 \%$, and order fulfillment cycle time tripled, but these metrics returned to previous levels after processes were reintegrated (Hammer, 2001). Dehning et al. (2007), have observed that many of the financial benefits of IT investments are in increased inventory turnover.

Less than full load shipments and empty trucks are expensive problems in freight transportation. Most refrigerated goods suppliers to supermarkets maintain dedicated transportation networks, despite lacking the scale operate them efficiently, resulting in suboptimal productivity (Hammer, 2001). Hammer also states that $20 \%$ of the US trucking fleet is travelling empty at any given time. Reduced batch sizes intended to reduce demand variability may exacerbate this problem, as a vehicle carrying small orders must make a larger number of deliveries in order to fully use capacity and time constraints limit the number feasible.

Unused information resources may be more difficult to recognize, but present nonetheless. Fisher et al. (2000) report that almost all retail buyers ignore unfavorable test results, often making excuses for why the data might be inaccurate. Duplication of efforts is also an issue when barriers between companies prevent the efficient transfer of information, as when Geon and its supplier OxyVinyls became unaware of one another's inventories, shipments, and demand levels (Hammer, 2001).

Relationships can also become unused resources, for example when buying power is dissipated through the supply chain as occurred at HP (Hammer, 2001), or when intermediaries (internal or external) try to recreate existing relationships independently, as occurred with the emarketplace described in Koch \& Schultze (2011).

\subsubsection{Inaccuracy}

Table 6. Inaccuracy

\begin{tabular}{lllll}
\hline Keyword & $\begin{array}{l}\text { Frequency } \\
(\mathrm{n}=110)\end{array}$ & Resource & Example Problems & Example Solutions \\
\hline Inaccuracy & 8 & Information & $\begin{array}{l}\text { When placing/processing orders, POS } \\
\text { data, forecasting, shortage } \\
\text { gaming/speculation, negotiable prices }\end{array}$ & $\begin{array}{l}\text { Data validation rules, } \\
\text { real-time information } \\
\text { sharing, automation, } \\
\text { rather than best offers in a marketplace } \\
\text { allocate scarce goods on } \\
\text { past sales (not current } \\
\text { orders) }\end{array}$ \\
\hline
\end{tabular}

Information inaccuracy, by nature, reduces the value of the information and the appropriateness of decisions made from it. Inaccuracies appear in POS data, due to a desire for speed over accuracy (Fisher et al, 2000); during order entry, for which manual processes may result in wrong prices, purchase order numbers, etc. (Hammer, 2001); and in forecasting, whether because of shortage gaming (Lee et al, 1997), or simply the fallibility of best judgment (Fryer, 2001).

3.2.6 Insufficient Resources

Table 7. Insufficient resources

\begin{tabular}{lllll}
\hline Keyword & $\begin{array}{l}\text { Frequency } \\
(\mathrm{n}=110)\end{array}$ & Resource & Example Problems & Example Solutions \\
\hline Insufficient & 10 & Inventory & Understaffed facility, & Incentives alignment, product mix \\
\hline
\end{tabular}




\begin{tabular}{|c|c|c|c|c|}
\hline \multicolumn{3}{|l|}{ Resources } & \multirow{2}{*}{$\begin{array}{l}\text { unavailable goods/services } \\
\text { (especially component } \\
\text { shortages) } \\
\text { Not enough variables } \\
\text { measured, not enough } \\
\text { information shared }\end{array}$} & \multirow{2}{*}{$\begin{array}{l}\text { variation by location, contingency } \\
\text { plans (e.g., steer consumer } \\
\text { demand, back-up suppliers) } \\
\text { CPFR, measure more variables } \\
\text { (e.g., zero-balance walk, } \\
\text { distribution of product returns) }\end{array}$} \\
\hline $\begin{array}{l}\text { Insufficient } \\
\text { Resources }\end{array}$ & 5 & Information & & \\
\hline $\begin{array}{l}\text { Insufficient } \\
\text { Resources }\end{array}$ & 5 & Relationship & $\begin{array}{l}\text { Insufficient skills to } \\
\text { implement technologies }\end{array}$ & $\begin{array}{l}\text { Mentoring programs, individual } \\
\text { development plans for employees }\end{array}$ \\
\hline
\end{tabular}

Insufficient inventory is more typically known as a shortage, or, in retail, a stockout. It occurs when demand is greater than immediately available supply for a given good or service, and is most frequently cited in a context of component shortages (e.g., when a fire in a supplier plant caused a delayed product launch, Lee (2004)). This problem type may sound simpler than it is in practice, as Bryan Stolle of Agile Software explains: "It's not enough to make sure you have back up suppliers. When component supplies run low, nobody has any" (Fryer, 2001).

Insufficient information occurs when too little data is available to optimize a given decision making process. This may be a result of measuring too few variables (e.g., Dairy Farm Group's POS did not catch all the details of customer transactions (Farhoomand et al., 1999)), or because too little information is shared across organizational or departmental boundaries (e.g., a purchasing department did not have access to inventory level information in Barratt \& Barratt (2011)). The importance of return flows is increasing (van Hillegersberg et al., 2001); higher rates of returns are experienced in e-commerce, sometimes caused by insufficient or inaccurate information available to customers (Rabinovich et al., 2010).

Insufficient resources in a relationship context mean that a supply chain partner is lacking some useful attribute. Interestingly, in nearly all of the examples cited this attribute was a technical skill (e.g., Covisint had difficulties training buyers and suppliers in the use of its products (Rosenzweig \& Roth, 2007)). A possible explanation is that the absence of interpersonal skills might be more easily observed through resulting conflicts.

3.2.7 Long Tail

Table 8. Long tail

\begin{tabular}{|c|c|c|c|c|}
\hline Keyword & $\begin{array}{l}\text { Frequency } \\
(\mathrm{n}=110)\end{array}$ & Resource & Example Problems & Example Solutions \\
\hline $\begin{array}{l}\text { Long } \\
\text { Tail }\end{array}$ & 5 & Inventory & $\begin{array}{l}\text { High inventory costs and stockouts, } \\
\text { impossible to stock all parts at all } \\
\text { distributors }\end{array}$ & $\begin{array}{l}\text { Incentives alignment, SKU } \\
\text { rationalization, shared inventory } \\
\text { systems }\end{array}$ \\
\hline
\end{tabular}

Long tail is a term that refers to a sales distribution wider than the typical $80 / 20$ Pareto distribution. This has been observed in e-commerce (Rabinovich et al., 2011). Long tails, like demand fluctuations, result in both high inventory levels and shortages - the difference is that with long tails both can happen at the same time. This sales distribution is typical of some industries, such as providing parts for customizable machinery (e.g., conveyor belts at Dunlop-Enerka (Narus \& Anderson, 1996)). A successful approach has involved pooled resources, which means that each distributor is able to provide many more parts than those that it carries itself. When a long tail distribution is not inherent to the industry, SKU rationalization may be a better approach (e.g., Pellton International produced more than 2000 SKUs despite producing a commodity product due to variation in sizes and packaging (Corbett et al., 1999)).

3.2.8 Pricing

Table 9. Pricing

\begin{tabular}{lllll}
\hline Keyword & $\begin{array}{l}\text { Frequency } \\
(\mathrm{n}=110)\end{array}$ & Resource & Example Problems & Example Solutions \\
\hline Pricing & 9 & Product & $\begin{array}{l}\text { High labour costs for } \\
\text { manual intervention, poor }\end{array}$ & $\begin{array}{l}\text { Automation, standardization and } \\
\text { integration of IT, adaptability and }\end{array}$ \\
\hline
\end{tabular}




\begin{tabular}{|c|c|c|c|c|}
\hline & & & $\begin{array}{l}\text { cost/benefit weighting, high } \\
\text { prices relative to } \\
\text { competitors }\end{array}$ & agility, careful measuring of trade-offs \\
\hline Pricing & 8 & Relationship & $\begin{array}{l}\text { Imperfect revenue models, } \\
\text { pricing pressure from } \\
\text { partners, outdated contracts } \\
\text { (esp. IT outsourcing), } \\
\text { switching costs }\end{array}$ & $\begin{array}{l}\text { Incentives alignment, alignment of } \\
\text { technology and organizational factors, } \\
\text { short contracts and multiple suppliers or } \\
\text { long partnerships with few suppliers, } \\
\text { maintain control of core processes }\end{array}$ \\
\hline
\end{tabular}

Supply chain product pricing problems are generally rooted in imperfect inter-enterprise processes that drive up the price of the end product. Excessive order management costs seem to be particularly common, and easily solved through automation (e.g., \$233 per order in handling costs at IBM (Hammer, 2001)). Other problems in this category include poor cost-benefit weighting (e.g., only bulk orders were made for steam traps, despite the high ongoing costs of leaks (Smith, 2000)), high relative materials costs (e.g., at Compaq due to a slow channel (Lee, 2004)), and suboptimal surcharges (e.g., an interviewee explained that applying appropriate surcharges to specific lanes and areas was prohibitively complex in Manuj \& Sahin, 2011).

Relationship pricing problems involve less targeted problems than those above, ones that affect every interaction between the companies rather than specific areas. Heavy pressure from retailers to continually reduce costs can seriously harm a manufacturer, as it did at Goodyear after that firm outsourced control of distribution to big box retailers (Thomas \& Wilkinson, 2006). Relationship specific investments are a solution in some cases, as they allow suppliers to retain more of the value generated by their IT use when it would otherwise be bargained away in negotiations (Subramani, 2004). Revenue models for intermediaries may fail to account for true contributions, as with the utilities marketplace described in Koch and Schultze (2011) and thereby fail to optimize output levels. Characteristics such as innovation, adoption of new technology, quality, information exchange, trust, flexibility, and responsiveness are difficult to enforce contractually and must be incentivized in some other fashion, such as by increasing the bargaining power of suppliers (Bakos \& Brynjolfsson, 1993). Long contracts with a single supplier also create problems by making a company vulnerable to escalating fees and inflexible services (Cross, 1995). Some products, such as commercial off the shelf software, by nature involve high switching costs (Brereton, 2004), which are clearly a problem for those companies which, like Samsung Electronics, recognize an inadequate fit between the product and the business processes (Singh et al., 2007).

\subsubsection{Security}

Table 10. Security

\begin{tabular}{lllll}
\hline Keyword & $\begin{array}{l}\text { Frequency } \\
(\mathrm{n}=110)\end{array}$ & Resource & Example Problems & Example Solutions \\
\hline Security & 4 & Information & $\begin{array}{l}\text { Opportunistic behavior, } \\
\text { information leaked by } \\
\text { partners }\end{array}$ & $\begin{array}{l}\text { Relationship-specific investments, } \\
\text { joint relationship effort }\end{array}$ \\
\hline
\end{tabular}

The security problems found involved the fear of information leaks decreasing the flow of proprietary information and best practices between firms. As such, the solutions recommended for these problems are methods for increasing trust, rather than eliminating security threats. Trust increases information flows and plays an important role in supply chain governance (Ghosh \& Fedorowicz, 2008). As Dyer and Singh state, "governance plays a key role in the creation of relational rents because it influences transaction costs, as well as the willingness of alliance partners to engage in value-creation initiatives" (p 669, 1998). Governance mechanisms include both legal and self-enforcing ones; those that are self-enforcing and informal (e.g., trust) are likely to be the most effective (Dyer \& Singh, 1998). Security issues from parties outside the supply chain are not considered supply chain problems here as no references were found to them in the supply chain literature.

\subsection{Application}

This classification scheme may be used by both practitioners and academics for the assessment of problems and solutions. Either party may begin with a problem for which a solution is sought, or may begin with a solution for which an assessment of applicability to some problem is sought. Our work should be equally useful from both directions. Examples of approaches from each direction follow. 


\subsubsection{Problem as Starting Point}

This example of application with problem as starting point uses "demand fluctuation", which is the most frequently cited problem type. Plausibly, one might begin with a set of symptoms, e.g., high inventory costs and stockouts both occurring in a single product line. Using Table 2, two problem types would stand out as candidates: long tail, and demand fluctuation. The next step would be to look at the other characteristic signs of each candidate problem, i.e., does the situation also involve any of either a) the bullwhip effect, long production cycles, or product defects, or b) a very large or varied product line, or a product line with very high item costs. For this example we are dealing with demand fluctuation, which corresponds with the former.

Problem identification complete, the next step in applying this typology is to assess the potential applicability of solutions used by other companies or recommended in the literature. These include some solutions that would work for a wide variety of situations and industries, such as improving forecasting methods and aligning incentives, as well as more targeted solutions such as flexible manufacturing, eliminating promotions, and creating consortia for sharing resources. Once one or more feasible solutions have been identified, the appendix to our work may be used to identify the applicable article(s) for further detail.

\subsubsection{Solution as Starting Point}

For an example of application using a solution as starting point, we use incentive alignment. Incentive alignment is the method which was used or recommended for solving the broadest number of problem types. In evaluating the applicability of a solution, one can systematically assess each problem type, going further in depth as prudent. For each problem type one might ask whether or not the solution was used to solve the problem in the referenced literature. If the answer is no, then a follow up question might be whether or not the solution is a plausible solution for the problem type under consideration.

In the example of incentive alignment, the term appears verbatim in the tables for the following problem types (resource affected is in brackets where multiple are possible): conflict, delays (freight), demand fluctuation, excess/unused resources (inventory), insufficient resources (inventory), long tail, and pricing (relationship). The problems of excess/unused freight and inaccurate information are only slightly more difficult to associate with the solution of incentive alignment; both problems reference specific forms of incentive alignment. For example, the recommendation to prevent shortage gaming by allocating scarce goods based on past sales rather than outstanding orders (Lee et al., 1997) is a way of eliminating the incentive to provide inaccurate demand information.

Incentive alignment is not listed in regards to delays (information), excess/unused resources (information and relationships), insufficient resources (information and relationships), pricing (product) or security. As per the follow-up question, the next step is to assess its applicability to these problems; several of the security problem references were not accompanied by recommended solutions, which provides a good starting point. BP Exploration's multiple IT suppliers were reluctant to share best practices with one another as they were also competitors (Cross, 1995). It is easy to envision this problem being solvable with suitable incentives. Similarly, when General Electric suppliers were not ready to do business online (Barua et al, 2004) they likely would have been happy to develop those skills had their incentives been aligned to favour such investments, which indicates that incentive alignment is also capable of solving problems with insufficient relationship resources. Incentive alignment seems to be a less optimal solution for the remaining problem types. In the category of pricing (product), for example, the problem of excess order management costs might be improved with incentive alignment, perhaps by making order processing time a key performance indicator for employees, but such a tack seems inferior to the technological solutions used by the firms in question (Hammer, 2001; Lee et al, 1997). Thus it appears that incentive alignment is broadly applicable to a wide variety of problem types, but it is not a universally ideal solution to supply chain problems.

\section{$4 \square$ Discussion}

\subsection{Managerial Implications}

One of the lessons taught in lean production is that "problems should be identified as frequently as possible, as early as possible" (p 388, Staats et al., 2011). Our classification scheme for supply chain problems can guide managers in that vital first step. Clear problem identification may help to identify appropriate technological solutions. For example, collaborative planning, forecasting and replenishment (CPFR) can be enormously helpful with demand fluctuations, but might be of little use in a supply chain plagued by conflict. 
In addition, managers experiencing supply chain problems should be able to easily identify other companies which have suffered similar situations and, with follow-up research, can learn from the results of the applied solutions of those parties.

Qualitatively, industry sector and product do not appear to significantly change the distribution of supply chain problems. As such, all managers should take a broad view of their supply chains and be aware that any of these issues could arise in their field.

\subsection{Conclusions}

This research has developed a natural pattern of supply chain problems with nine distinct keywords, which create sixteen subcategories when their varying effects on different resources in the supply chain are taken into account. Supply chain problems include those that affect the material flow (delays, demand fluctuations, excess/unused resources, insufficient resources, long tail, and pricing), the information flow (delays, excess/unused resources, inaccuracy, insufficient resources, and security), and relationships (conflict, excess/unused resources, insufficient resources, and pricing). Although the number of categories is slightly unwieldy, it is appropriate for the stated purpose of presenting a comprehensive picture. Categories could have been further amalgamated, for example into super-categories of time, quantity and quality issues, but this would only conceal the true range of problems.

Previously in supply chain management literature, problems have been discussed on a very narrow level while solutions have been examined quite broadly. This classification scheme successfully narrows the gap between these two areas by amalgamating supply chain problems into categories which retain their diversity without being so numerous as to prevent discussion from the broader solutions perspective.

\subsection{Limitations}

As the sample was gathered from extant supply chain research, then it reflects patterns of that research (e.g., the disproportionate representation of the electronics and manufacturing sectors). In particular, as the problems addressed here are only those which have been addressed in the recent literature, it is possible that some prevalent but uninteresting problem exists which has been left out of the dataset due to a lack of research on the topic. It is similarly possible that some problem which has been covered in the literature has been missed due to the infeasibility of examining every supply-chain related publication of recent decades.

If the supply chain problems analyzed had been collected directly from industry, the data would be more direct, and potentially create an even more comprehensive picture. With industry data the proposed category set could be tested, and the distribution of problems could be estimated. It would also be interesting to measure correlations between problems, as it is logically evident that problems such as inaccurate information can lead to suboptimal inventory quantities. That said, this literature-based methodology also contributes value, which would not be provided by survey-based work, by gathering and organizing academic findings in a concise and accessible fashion.

\section{Acknowledgements}

We thank the Natural Science and Engineering Research Council of Canada, the Robson Professorship Endowment, and the Informatics Research Center in the Haskayne School of Business at the University of Calgary for support.

\section{References}

Andriole, S. J. (2006). The Collaborate/Integrate Business Technology Strategy. Communications of the ACM, 49(5), 85-90. http://dx.doi.org/10.1145/1125944.1125946

Bakos, J. Y., \& Brynjolfsson, E. (1993). Information technology, incentives, and the optimal number of suppliers. Journal of Management Information Systems, 10(2), 37.

Barua, A., Konana, P., Whinston, A. B., \& Yin, F. (2004). An empirical investigation of net-enabled business value. MIS Quarterly, 28(4), 585-620.

Baraldi, E. (2008). Strategy in Industrial Networks: Experiences from IKEA. California Management Review, 99-126.

Barratt, M., \& Barratt, R. (2011). Exploring internal and external supply chain linkages: Evidence from the field. Journal of Operations Management, 29(5), 514. http://dx.doi.org/10.1016/j.jom.2010.11.006

Barratt, M., \& Oke, A. (2007). Antecedents of supply chain visibility in retail supply chains: A resource-based $\begin{array}{lllll}\text { theory perspective. Journal of Operations Management, } & 25(6), & 1217 .\end{array}$ http://dx.doi.org/10.1016/j.jom.2007.01.003 
Bean, J. P., \& Kuh, G. D. (1984). A Typology of Planning Problems. Journal of Higher Education, 55(1), 35-55. http://dx.doi.org/10.2307/1980971

Brereton, P. (2004). The software customer/supplier relationship. Association for Computing Machinery. Communications of the ACM, 47(2), 77-81. http://dx.doi.org/10.1145/966389.966394

Burgess, K., Singh, P. J., \& Koroglu, R. (2006). Supply chain management: a structured literature review and implications for future research. International Journal of Operations \& Production Management: Supply chain management theory and practice, 26(7), 703-729.

Cachon, G., Randall, T., \& Schmidt, G. (2007). In Search of the Bullwhip Effect. Manufacturing \& Service Operations Management, 9(4), 457-479. http://dx.doi.org/10.1287/msom.1060.0149

Carper, W. B., \& Snizek, W. E. (1980). The nature and types of organizational taxonomies: An Overview. Academy of Management. Academy of Management Review, 5(1), 65.

Cattani, K., Dahan, E., \& Schmidt, G. (2005). Offshoring Versus "Spackling". Sloan Management Review, 46(3), 6-7.

Cha, H., Pingry, D., \& Thatcher, M. (2008). Managing the knowledge supply chain: an organizational learning model of information technology offshore outsourcing. MIS Quarterly, 32(2), 281.

Cole, R. (2011). What Really Happened to Toyota?. Sloan Management Review, 52(4), 29-35.

Corbett, C. J., Blackburn, J. D., \& Van Wassenhove, L. N. (1999). Partnerships to Improve Supply Chains. Sloan Management Review, 40(4), 71-82.

Corsten, D., \& Kumar, N. (2003). Profits in the Pie of the Beholder. Harvard Business Review, 81(5), 22-23.

Cross, J. (1995). IT outsourcing: British Petroleum's competitive approach. Harvard Business Review, 73(3), 94.

De Leeuw, S., Holweg, M., \& Williams, G. (2011). The impact of decentralised control on firm-level inventory. International Journal of Physical Distribution \& Logistics Management, 41(5), 435-456. http://dx.doi.org/10.1108/09600031111138817

Dehning, B., Richardson, V. J., \& Zmud, R. W. (2007). The financial performance effects of IT-based supply chain management systems in manufacturing firms. Journal of Operations Management, 25(4), 806. http://dx.doi.org/10.1016/j.jom.2006.09.001

Doty, D. H., \& Glick, W. H. (1994). Typologies as a unique form of theory building: Toward improved understanding and modeling. Academy of Management Review, 19(2), 230.

Dyer, J. H., \& Singh, H. (1998). The relational view: Cooperative strategy and sources of interorganizational competitive advantage. Academy of Management Review, 23(4), 660-679.

El Sawy, O. A., Malhotra, A., Gosain, S., \& Young, K. M. (1999). IT-intensive value innovation in the electronic economy: Insights from Marshall industries. MIS Quarterly, 23(3), 305-335. http://dx.doi.org/10.2307/249466

Farhoomand, A. F., Ng, P., Ng E., \& Banerjee, P. (1999). Dairy Farm Group - Redesign of Business Systems and Processes [case study]. Boston: Harvard Business Publishing.

Fisher, M. L., Raman, A., \& McClelland, A. (2000). Rocket Science Retailing Is Almost Here: Are You Ready?. Harvard Business Review, 78(4), 115-124.

Fischhoff, B. (1975). Hindsight $\neq$ foresight: The effect of outcome knowledge on judgment under uncertainty. Journal of Experimental Psychology: Human Perception \& Performance, 1, 288-299. http://dx.doi.org/10.1037/0096-1523.1.3.288

Fryer, B. (2001). Competing for supply [interview with Bryan Stolle, chairman and CEO of Agile Software]. Harvard Business Review, 79(2), 25-26.

Ghosh, A., \& Fedorowicz, J. (2008). The role of trust in supply chain governance. Business Process Management Journal, 14(4), 453-470. http://dx.doi.org/10.1108/14637150810888019

Greis, N. P., \& Kasarda, J. D. (1997). Enterprise logistics in the information era. California Management Review, 39(4), 55-78.

Gunasekaran, A., \& Ngai, E. W. T. (2005). Build-to-order supply chain management: a literature review and framework for development. Journal of Operations Management, 23(5), 423-451. http://dx.doi.org/10.1016/j.jom.2004.10.005 
Hammer, M. (2001). The Superefficient company. Harvard Business Review, 79(8), 82-91.

Klein, R., \& Rai, A. (2009). Interfirm strategic information flows in logistics supply chain relationships. MIS Quarterly, 33(4), 735.

Koch, H., \& Schultze, U. (2011). Stuck in the conflicted middle: a role-theoretic perspective on B2B e-marketplaces. MIS Quarterly, 35(1), 123.

Lee, H. L. (2004). The triple-a supply chain. Harvard Business Review, 82(10), 102-112.

Lee, H. L., Padmanabhan, V., \& Seungjin, W. S. (1997). The Bullwhip Effect in Supply Chains. Sloan Management Review, 38(3), 93-102.

Liu, G. J., \& Deitz, G. D. (2011). Linking supply chain management with mass customization capability. International Journal of Physical Distribution \& Logistics Management, 41(7) http://dx.doi.org/10.1108/09600031111154125

Manuj, I., \& Sahin, F. (2011). A model of supply chain and supply chain decision-making complexity. International Journal of Physical Distribution \& Logistics Management, 41(5), 511-549. http://dx.doi.org/10.1108/09600031111138844

Myers, M., \& Cheung, M. (2008). Sharing Global Supply Chain Knowledge. Sloan Management Review, 49(4), 67-73.

Narayanan, V. G., \& Raman, A. (2004). Aligning Incentives in Supply Chains. Harvard Business Review, 82(11), 94-102.

Narus, J. A., \& Anderson, J. C. (1996). Rethinking distribution: Adaptive channels. Harvard Business Review, 74(4), 112.

Nickols, F. W. (1996). Yes, it makes a difference. Quality Progress, 29(1), 83.

Rabinovich, E., Dresner, M. E., \& Evers, P. T. (2003). Assessing the effects of operational processes and information systems on inventory performance. Journal of Operations Management, 21(1), 63-80. http://dx.doi.org/10.1016/S0272-6963(02)00041-4

Rabinovich, E., Sinha, R., \& Laseter, T. (2011). Unlimited shelf space in Internet supply chains: Treasure trove or wasteland? Journal of Operations Management, 29(4), 305. http://dx.doi.org/10.1016/j.jom.2010.07.002

Rai, A., Patnayakuni, R., \& Seth, N. (2006). Firm Performance Impacts of Digitally Enabled Supply Chain Integration Capabilities. MIS Quarterly, 30(2), 225-246.

Rice, J. (2011). Only as Strong as the Weakest Link. Mechanical Engineering, 133(6), 26-31.

Richard, P. J., \& Devinney, T. M. (2005). Modular Strategies: B2B technology and architectural knowledge. California Management Review, 47(4), 86-113.

Rosenzweig, E. D., \& Roth, A. V. (2007). B2B seller competence: Construct development and measurement using a supply chain strategy lens. Journal of Operations Management, 25(6), 1311. http://dx.doi.org/10.1016/j.jom.2007.01.007

Scherpereel, C. M. (2006). Decision orders: a decision taxonomy. Management Decision, 44(1), 123-136. http://dx.doi.org/10.1108/00251740610641508

Schoenherr, T., \& Mabert, V. (2008). The use of bundling in B2B online reverse auctions. Journal of Operations Management, 26(1), 81. http://dx.doi.org/10.1016/j.jom.2007.05.001

Short, J. E., \& Venkatraman, N. (1992). Beyond Business Process Redesign: Redefining Baxter's Business Network. Sloan Management Review, 34(1), 7.

Singh, N., Lai, K., \& Cheng, T. C. E. (2007). Intra-organizational perspectives on IT-enabled supply chains. Association for Computing Machinery. Communications of the ACM, 50(1), 59-65. http://dx.doi.org/10.1145/1188913.1188918

Slone, R. (2004). Leading a Supply Chain Turnaround. Harvard Business Review, 82(10), 114-121.

Smith, G. F. (2000). Too many types of quality problems. Quality Progress, 33(4), 43-49.

Staats, B., Brunner, D., \& Upton, D. (2011). Lean principles, learning, and knowledge work: Evidence from a software services provider. Journal of Operations Management, 29(5), 376. http://dx.doi.org/10.1016/j.jom.2010.11.005 
Subramani, M. (2004). How do suppliers benefit from information technology use in supply chain relationships? MIS Quarterly, 28(1), 45-73.

Thomas, A. R., \& Wilkinson, T. J. (2006). The Outsourcing Compulsion. Sloan Management Review, 48(1), $10-14$.

Van Hillegersberg, J., Zuidwijk, R., Van Nunen, J., \& Van Eijk, D. (2001). Supporting return flows in the supply chain. Communications of the ACM, 44(6), 74-79. http://dx.doi.org/10.1145/376134.376172

Weeks, M. R., \& Feeny, D. (2008). Outsourcing: From cost management to innovation and business value. California Management Review, 127-146.

Zhang, C., Henke, J., \& Griffith, D. (2009). Do buyer cooperative actions matter under relational stress? Evidence from Japanese and U.S. assemblers in the U.S. automotive industry. Journal of Operations Management, 27(6), 479. http://dx.doi.org/10.1016/j.jom.2009.04.001 